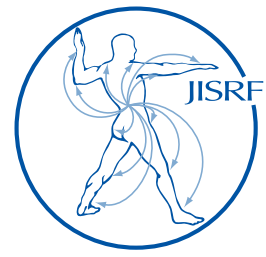

\title{
Return to Work Following Total Knee Replacement
}

\author{
Cameron $\mathrm{H}^{1}$
}

\section{Abstract}

The length of time to return to work after Total Knee Replacement is often treated as a monolithic entity. Figures produced under such an assumption are interesting but have little practical value in individual cases.

Numerous factors most of which are not under medical control are involved. What is clear however is that the timing of surgery is of considerable importance in a job specific situation and this is under medical control.

\section{Introduction}

There have been many attempts to quantify the average time of return to work following total knee replacement as clearly, this information is of value to the patient, the employer, the insurance company, etc. There are a fair number of publications on this issue, but they are of variable quantity and value.

Tilbury (2013) [1] attempted to analyze the data in the literature. They found 796 references. For a variety of reasons such as inadequate numbers, inadequate followup, etc. 19 papers only were finally accepted for inclusion.

Even here, there are numerous objections, the main one being that return to work is seen as some monolithic entity into which all patients fit. Clearly, this is not the case and there are numerous factors involved, which may not be seen initially as being terribly significant and, therefore, the data is simply not there when a retrospective chart review is being undertaken.

Total knee replacement is an operation, which requires a certain recovery time. Numerous factors influence this. This has been studied and reported in broad terms only. Lombardi [르 in the U.S. noted the average return to work was about three months, whereas Cameron [ $\underline{3}]$ in Canada found a time twice as long. On comparing notes, it became clear that the main factor was the duration of benefits.

There are a large number of subgroups, who need to be selected out before much can be said about the average length off work following a knee replacement. For example, if the wrong time of year is picked to do the knee replacement and the patient not given adequate time to recover, they may remain off work an inordinate length of time and indeed, they may be forced into retirement, etc. The timing of surgery in many of these jobs is, therefore, of importance. Some of these jobs will be examined and

Keywords: Total Knee Replacement; return to work; employment influence; timing of total knee replacement

Level of Evidence: AAOS Therapeutic Level V
1 H.U. Cameron, MBChB, FRCS(C)

Associate Prof., Department of Surgery U of Toronto. Staff orthopaedic surgeon, Holland Arthritis Center, 43 Wellesley Street E, Toronto, M4Y $1 \mathrm{H} 1$

(Direct reprint requests to Hugh Cameron)
(C) 2017 Cameron. All rights reserved.

Authors retain copyright and grant the journal right of first

publication with the work. Reconstructive Review is an open ac- OPEN 6 ACCESS cess publication and follows the Creative Commons Attribution-

NonCommercial CC BY-NC. This license allows anyone to download works, build upon the material, and share them with others for non-commercial purposes as long as they credit the senior author, Reconstructive Review, and the Joint Implant Surgery \& Research Foundation (JISRF). An example credit would be: "Courtesy of (senior author's name), Reconstructive Review, JISRF, Chagrin Falls, Ohio”. 
the obvious date of prospective surgery pointed out.

\section{Seasonal-Farmers}

Depending on geography and the type of farming in general, the farmer should have his knee replaced in November, which will give him a reduce workload until spring. If his knee is replaced in the summer and he will be forced into the unenviable situation of trying to cope with a harvest and a painful knee at the same time, which can be extremely difficult.

\section{Retail}

The patient will know and should be asked their busy time. For most, it is winter/spring and they should, therefore, be done in late spring. There are sports stores, however, which tend to be most busy in the spring when customers are outfitting for summer and in fall when they are outfitting for winter. The patient should be able to provide an indicator of when the surgery should be carried out.

\section{Real Estate}

Commercial real estate really does not change, but residential does. The busiest time of year is spring so that the real estate sales person should be done in the fall. There is a significant difference between the rural and urban real estate as stairs in the country tend to be more difficult with higher risers and a narrower tread and sometimes access to the property may be difficult.

\section{Landscaping}

This used to be seasonal, but most northern landscapers now do snow removal in the winter. There is a fairly narrow window of time in the spring and fall. The fall is preferable. Snow removal is lighter than landscaping.

\section{Construction Industry}

This used to be very seasonal as concrete would not set below a certain temperature. Technology, however, has solved that problem and while construction may slow in the winter, it does not stop.

\section{Restaurants}

In general, there is no good time for the restaurateur. If the boss is not there, things go missing. Some restaurants experience a slow-down, especially in the summer and some may even close for a few weeks.

\section{Teachers}

Teachers have long summer holidays. Teachers should be booked for surgery in the last two weeks in June when the holidays begin, which will give them until September to recover. Early childhood educators/daycare are paradoxically most busy in the summer.

There are many other niche occupations such as commercial diving, trapping, beef cattle farming and Great Lakes Commercial Sailing. A discussion needs to be had with these people regarding the optimum time for surgery.

There are other factors of considerable importance in terms of time to return to work. These observations are obviously generalizations and are certainly not true in every case, but generalizations are just that, i.e. they are generally fairly accurate.

\section{Public versus Private}

Public sector workers take far longer to return to work than private sector workers.

Public employees at all levels of government have benefits, which far outweigh those in the private sector. As a rule of thumb, for an identical job, it will take a public sector worker much longer to return to work.

In the private sector, there is always a push to get the patient back to work, which simply does not exist within the public system.

\section{Pension/Retirement}

This again tends to be more for public sector type jobs. The patient frequently knows exactly how long they have to work for full pension. Occupations such as nursing, police and fire fighting etc. will frequently request surgery about one year before anticipated retirement as their short term benefits, at least in Canada, accompanied by some long term benefits, will serve as a bridge before old age pension or other pension becomes available. Many of these jobs also allow the banking of sick days of up to one year. This was also true with the large unions in the car plants.

\section{Actors/Entertainers}

Elderly entertainers nearing the end of their working life usually have no pension and few savings. They do fortunately, usually have a wide circle of friends for social back-up. If they get a phone call from their agent about a "gig" (job), they may be under enormous pressure to accept it. Fortunately, these parts tend to be of short duration and relatively infrequent and, therefore, while they may delay rehabilitation, most patients cope.

\section{Early Dementia/Placement}

Pre-surgical conferences should be held with the family. Advanced dementia is recognized by all so realistic a return to work and or placement conference can be held in the early stage. However, dementia is frequently unrecog- 
nized/denied by the family and the surgical team simply does not know. This can become a major problem following surgery. A return to work may be completely unrealistic.

If the patient has lived alone, they may no longer be able to do so. This results in a frantic search for a nursing home. Nursing homes in Canada are in short supply and have very long waiting lists, especially if supplementary financing is not available.

If the patient was in a nursing home, following surgery, they may need an increased level of care and that nursing home may not be appropriate. There is also a policy, which may be peculiar to Canada, which states that if the bed is not occupied within four days, the patient will lose it.

Placement then again becomes a major issue and a source of considerable conflict. The patient cannot stay in an acute hospital, although frequently they do. The staff quickly recognizes the inappropriateness of the situation and pejorative terms such as "bed blocker" begin to be used. Convalescent hospitals will not accept them as they are really not convalescent. The family may come under immense pressure by the hospital to place the patient. Recognizing the futility or impossibility of such a situation, the family, which may be a skip generation, i.e. the grandchildren, may choose to simply walk away. Those working at the sharp edge of medical care find it hard to blame the family.

Placement in these cases is becoming increasingly a major problem, which is not being faced by government at any level. The only government response seems to be to blame struggling nursing homes without providing any increased support or direction.

\section{The Legal Knee}

If there is a law suit involved as a result of a car accident, etc., it is important to know the status of the law suit. If the case has not settled and the patient goes back to work, then clearly, the settlement will be less than otherwise would be the case.

\section{The Workmen's Compensation Board Knee}

The surgeon must recognize before operating on a Workmen's Compensation Board case that these cases are different from the normal knee case. It is unlike that the patient is going to admit to complete recovery, and will likely continue to complain of pain forever which may be an issue.

The Workmen's Compensation knee has been fairly extensively studied. Clyde (2013) [4]. It seems to be generally agreed that about 70 percent return to work after primary joint arthroplasty versus 44 percent after revision. 67 percent of manual labourers return to work in about 16 weeks versus 85 percent in sedentary jobs.

This is data from the United States of America and as benefits vary considerably from one country to another, it should be seen as a broad indicator only.

\section{Fern Silverman Syndrome [3]}

The patient is highly educated, often at university level in her own country, but she has never learned to speak English so can only function within her own culture, which does not allow divorce. She has endless responsibilities including a full-time minimum wage job, all the cooking, all childcare and all homemaking and yard work. She is also responsible for looking after the parents on both sides of the family. After knee replacement, for the first time since marriage none of this is required. The chances of someone caught in this impossible situation returning to work is pretty remote.

\section{Prior Work Status}

Those who have not worked in the last few years are unlikely to return to work. Those, who have achieved some sort of a government disability pension, are equally unlikely. Once this exalted status is achieved, the government has no mechanism for further checks and balances.

It used to be thought that 70 percent income replacement would be required, but actually in Canada only 50 percent income replacement if often enough for many people never to return to work.

\section{Neuropathic Pain}

Complex regional pain syndrome type 2 is a nerve injury itself. It is extremely uncommon in knee replacement surgery. Type 1 or reflex sympathetic dystrophy [ [ $\underline{5}$ is fairly common. The author believes that such a condition exists, but others point out that the early diagnosis is difficult and easily gamed. They suggest that the diagnosis is dubious and can only be entertained in the absence of confounding factors. The chances of a return to work are slim.

\section{Insipient Osteoarthritis}

When a poor result presents, it is often instructive to obtain the original x-rays prior to surgery. One is often surprised how little arthritis was present prior to surgery. If there was not much arthritis pain as opposed to perceived pain prior to surgery, an operation is not likely to help and furthermore, even if obvious mechanical problems are present, a revision is equally unlikely to benefit the situation and the patient is equally unlikely to return to work. 


\section{Sepsis}

This will certainly delay return to work, but fortunately, nowadays is rare.

\section{Psychogenic Pain}

There are a variety of psychiatric conditions described, which will certainly influence the return to work. Fibromyalgia was a favourite diagnosis for a quarter of a century. This appears to have been replaced by a new theory of central sensitization. None of these are amenable to any particular treatment. Optimally, a speedy return to gainful employment is preferable, but it is unlikely.

There are full blown psychiatric conditions such as Conversion Disorders and a Somatic Symptom Disorder, which is the new name for a Pain Disorder.

\section{Further Factors of Significance}

Socioeconomic factors obviously are of significance Barrack (2014) []. Factors such as household income, education and employment, etc. play a significant role. The type of knee implant itself has no effect. Studies done on implants used years ago clearly are outdated.

\section{Discussion}

Once these subgroups are removed then one actually ends up with a relatively small number of patients. It is clear that surgery in and of itself, assuming no major complications, is not a significant factor. Return to work can- not be regarded as a monolithic entity and attempts made to quantify it as such will continue to produce data, which may be of some value in the overall sense, but does not really help in the practical sense.

\section{Treatment/Advice}

There really is little or nothing, which can be done to alter many of these outcomes. All one can hope to do is recognize them ahead of surgery and make appropriate provision.

One obvious answer in terms of speeding a return to work is a reduction in benefits. This is particularly true in the public system, but given the strength of the public service unions, that is unlikely to change.

A major future problem is likely to be the tidal wave of dementia for which no government at any level appears to be anticipating.

\section{References}

1. Tilbury, C., Wouters, Jose P. et al - Return to Work after Total Hip and Knee Arthroplasty: A Systemic Review, Rheumatology, 2014, 53512 - 525.

2. Lombardi, A.V., Nunley, R.M. and Barand, K.R. et al - Do Patients Return to Work After Total Knee Arthropasty, Clinical Clin Orthop Related Research, 2014197 Pages 138 - 146 .

3. Cameron, H.U., Wadey, V., Silverman, F. - The Post-Operative Painful Knee/Clinical and Societal Causes in Seminars in Arthropasty, 201526251 - 254.

4. Clyde, C.T., Goyal, N. and Matar, W. et al - Workmen's Compensation Board Patients after Total Knee Arthroplasty - Do They Return to Work, Journal of Arthroplasty, 2013, $28883-887$

5. Cameron HU. Park YS, Krestow M., Reflex Sympathetic Dystrophy following total knee replacement, Contemporary Orthopaedics, 1994, 24 279-281.

6. Barrack, R.L., Ruhel, Chen, J. - Impact of Socioeconomic Factors on the Outcome of Total Knee Arthroplasty, Clinical Orthopaedics and Related Research, 2014, 47286 to 97.

\section{Tissue Sparing Total Hip Arthroplasty Study Group}

The Joint Implant Surgery and Research Foundation has a long history in the study of THA. It began back in 1971 when Professor Charles O. Bechtol, M.D. established JISRF as a nonprofit scientific and educational foundation.

JISRF continues this study with the formation of a new study group of international surgeons and scientists. Findings will be posted on the foundation's web site at www.jisrf.org.

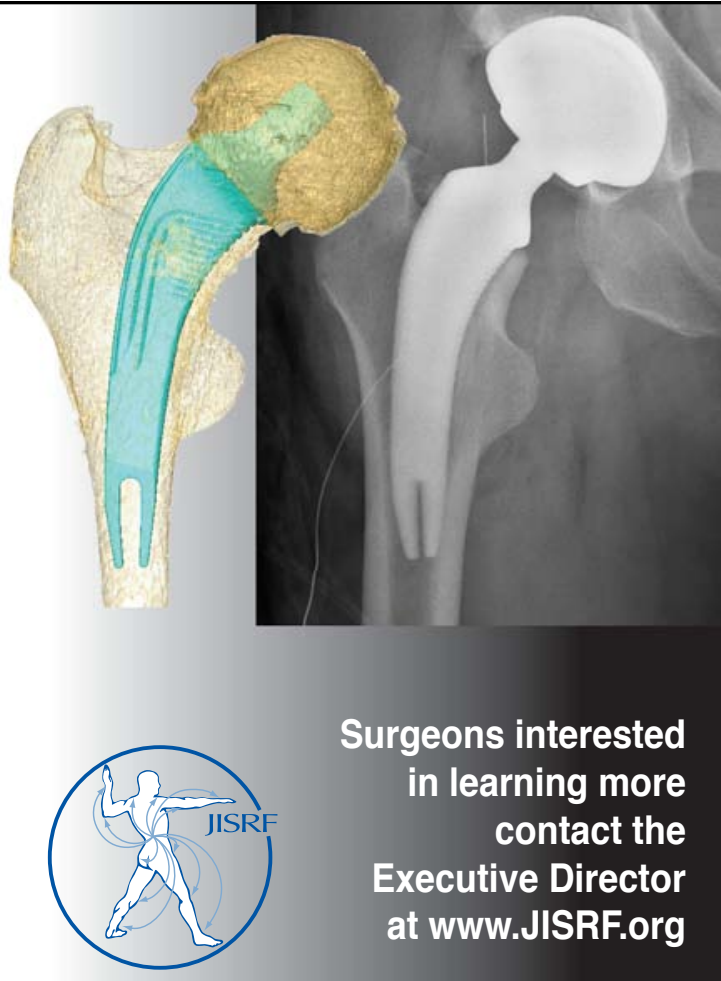

